\title{
En las orillas de la autoficción: las vacilaciones del autorrelato en textos de Sergio Pitol, Angelina Muñiz-Huberman y Alice Munro
}

\author{
Irene María ARTIGAS AlBARELLI \\ Universidad Nacional Autónoma de México
}

\begin{abstract}
La legobiografía, las seudomemorias y ciertos tipos de ficción son formas limítrofes que, al vacilar entre lo real y lo ficcional, los cuestionan y subvierten peculiarmente. A partir de la tensión esencial producida por ello, este ensayo analiza El arte de la fuga (1996) de Sergio Pitol, Molinos sin viento (2001) de Angelina Muñiz-Huberman y varios de los últimos relatos (2012) de Alice Munro, que ella misma ha separado de sus ficciones. La idea es subrayar qué les ocurre a nociones como las del ser, la memoria y la escritura debido a dicha vacilación.
\end{abstract}

Palabras ClaVe: legobiografía, seudomemorias, autoficción, Sergio Pitol, Angelina Muñiz-Huberman, Alice Munro.

Legobiography, pseudomemories, and some kinds of fiction are border forms that, staggering between the real and the fictional, question and subvert their limits. This essay analyzes how the peculiar tension provoked by this vacillation appears in Sergio Pitol's El arte de la fuga (1996), Angelina Muñiz-Huberman's Molinos $\sin$ viento (2001), and some of the last texts written (2012) by Alice Munro that she has put apart from her fictions. The idea is to see what this staggering does to notions such as being, memory, and writing.

KeYwords: legobiography, pseudomemories, autofiction, Sergio Pitol, Angelina Muñiz-Huberman, Alice Munro.

A partir de lo que ha escrito Manuel Alberca (2010) sobre la necesidad de situarse en el terreno del fingimiento para diferenciar la autoficción, definida como "una novela (o relato que se presenta como ficticio), cuyo narrador y/o personaje detenta la misma identidad nominal de su autor" (36), de otros relatos limítrofes del yo, olvidaré fingir y consideraré algunas de esas otras formas limítrofes: la legobiografía, las seudomemorias y ciertas formas de la ficción. La indeterminación genérica, la imprecisión del pacto de lectura, la vacilación que producen y el abanico de posibilidades esbozado por dicha vacilación, características todas presentes como ya se sabe en los textos autoficcionales, permitirán analizar este otro tipo de escritos que se mecen en las orillas de lo real y lo ficcional, y que las cuestionan y subvierten de una manera bastante peculiar. Quiero sobre todo centrarme en la situación planteada por Annick Louis de 
que existen textos que se leen "a la vez como ficción y como texto factual, sin decidir, sin rendirse ante el imperativo de una decisión, e incluso, sin desear decidir" (Louis, 2010: 92), y que producen una tensión esencial que vincula a este tipo de relatos con la concepción del ser, de la memoria y la escritura de sus autores.

Revisaré estos elementos en El arte de la fuga (1996) de Sergio Pitol, libro que fusiona el ensayo autobiográfico, el diario y la ficción; en Molinos sin viento (2001), una de las seudomemorias de Angelina Muñiz-Huberman, en donde se asume explícitamente que la memoria es parte de los paisajes imaginarios; y de diversos relatos de Alice Munro entre los que están algunos autobiográficos que ella ha separado de sus ficciones y descrito como "lo primero y lo último - y lo más cercano- que tengo que decir sobre mi propia vida" (Munro, 2012: 253).

\section{El arte de la fuga}

"Todo era de verdad, todo era cierto y, por desdicha, irrepetible" (Pitol, 1996: 58), escribe Sergio Pitol en este libro que puede leerse como memoria, ensayo autobiográfico, crónica de viajes, bitácora y poética aderezadas de ficción. Se trata de una colección de escritos, fechados y a veces publicados anteriormente en distintos foros, ordenados en cuatro partes que llevan los siguientes títulos: Memoria, Escritura, Lecturas y Final. El libro es una serie de malabarismos entre recuerdos de lo que le ocurrió en México y en el extranjero, de lo que le contaron que ocurrió, de lo que soñó que ocurrió, de lo que imaginó que ocurrió, de lo que leyó que ocurrió. Todo ello como una búsqueda por escribirse a sí mismo como era, como siguió siendo y como llegó a ser al escribir.

De 1965 dice, por ejemplo, en un ensayo fechado en 1996: "Evocar esa época no me hace pensar que "vivía yo otra vida", como por lo general se dice, sino más bien que la persona a quien me refiero no era del todo yo mismo; se trataba, en todo caso, de un joven mexicano que compartía conmigo el mismo nombre y algunos hábitos y manías" (Pitol, 1996: 15). La distancia entre aquel yo narrado y el yo que narra refuerza la noción de que todo lo que se cuenta era verdad y, al mismo tiempo, irrepetible. La desdicha de no poder repetir y de que cualquier repetición, entonces y siempre, desdice, parece estar detrás de lo que leemos. Y de lo que Pitol ha leído.

Irma Vélez (2003) considera que El arte de la fuga de Pitol se estructura en realidad en torno a lo que él ha leído: es una legobiografía (de lego "yo leo" sumado a la "escritura de la vida" de la biografía). Según ella, se trata de un discurso autobiográfico que puede tomar la forma de cartas, memorias, diarios, crónicas o autobiografías, protagonizado por un narrador que es también lector. Para Vélez "estudiar la legobiografía significa conceptualizar la auto-representación desde una identificación del sujeto como lector cuyo programa de lectura, dialógico e intertextual, se convierte en una

\footnotetext{
${ }^{1}$ Todas las traducciones de las citas de los textos de Alice Munro son mías.
} 
etapa fundamental tanto de la construcción de su subjetividad como de su textualidad" (2003: 150).

Vélez caracteriza la legobiografía como propensa a la pluralidad de registros genérico-textuales, lo cual explicaría la forma de El arte de la fuga. Se lee en retrospectiva una vida a través de la introspección familiar común en la autobiografía. También la forma está emparentada con la memoria, aunque en ella es la figura de la lectura la que legitima y valida la experiencia con consecuencias en lo escrito y en lo que se recuerda como vivido, lo que provoca anomalías cronológicas con lo supuestamente real, similares a las que describe Ana Casas para la autoficción. ${ }^{2}$ Para Vélez:

El lego de Pitol es autorreflexivo y se autocontempla a la luz de las lecturas hechas, a veces antes de tiempo o después de algún acontecimiento, como por ejemplo en su recuerdo de la última novela de Tabucchi, Sostiene Pereira, en vísperas de salir para Chiapas [a un viaje de tres o cuatro días que lo sacudió como si le quitaran treinta años de encima y que le provocó el surgimiento de un nuevo yo, así lo explica él, 20 de enero de 1994]. Resulta difícil al principio saber a qué le intenta dar sentido Pitol, si al desorden de sus lecturas o al curso azaroso de su destino (151-152).

Pitol fragua, entrama, la narración de su vida según el orden de lo que ha leído y de cómo eso lo constituye también como escritor. Él dice:

Como Tolstoi, puedo sólo escribir sobre lo que he vivido. Mis narraciones han sido un cuaderno de bitácora que registra mis movimientos. Un espectro de mis preocupaciones, momentos felices y desafortunados, lecturas, perplejidades y trabajos. E, igual que Beckmann, estoy convencido de que lo vivido tiene que someterse a un proceso discriminatorio. La selección de materiales tiene que coincidir con la aparición de una forma (1996: 125).

Y es esa forma y su aparición la que encuentra y se encuentra en su "arte de la fuga". Pitol se escribe a partir de la hipnosis, de "la temperatura absolutamente personal", de ademanes, de "fantasmas que pululan en el subsuelo", hace "cuadernos de bitácora" que registran sus viajes entre países y entre géneros, su antipatía ante el poder. "La pasión por la lectura y la antipatía a cualquier manifestación del poder definen la identidad entre quien soy y quien fui entonces", escribe también en 1996 sobre 1965 (1996: 16).

Vélez elucubra que detrás del libro de Pitol se encuentra Les Mots de Sartre. Y que la elipsis a mencionarlo, entre todas las alusiones y citas que hace a innumerables escritores franceses contemporáneos a Sartre, puede deberse a un juego carnavalesco que estructura el libro de Pitol y que también es reflejo de la indeterminación

\footnotetext{
${ }^{2}$ Ana Casas advierte ciertas estrategias discursivas que en la novela autoficcional se usan y que se toman de la novela contemporánea, a saber, "a) la intensificación de la manipulación del orden cronológico, b) la alternancia de voces y los cambios de focalización y c) la presencia del autocomentario o metadiscurso" (2010: 194).
} 
genérica. Vélez apunta un fragmento del libro de Sartre en el que se refiere a El arte de la fuga de Bach y en el que concluye que su identidad es un "bien cultural" que la "cultura lo impregna y se lo devuelve a la familia por proyección, como los estanques devuelven, en la noche el calor del día" (Sartre, cit. por Vélez, 2003: 153). Una autorreflexividad semejante, tanto de la forma de la fuga como del libro de Sartre, fundamenta el libro de Pitol. Él es en términos de lo que lee, lo que habla con sus amigos, lo que inventa, lo que sueña o lo que descubre de sí gracias al hipnotismo... La fuga musical, nos recuerda Vélez, tiene su origen en la polifonía del siglo XIII y, aunque no se reconociera como tal sino hasta después (XVI), tiene un carácter imitativo en el cual

[...] el sujeto constituye la idea unificadora y el punto central de interés. Tanto la legobiografía de Pitol como la de Sartre, en sus reflexiones sobre la escritura y la lectura, reflejan un intento de composición literaria de la fuga. Ambos de manera muy diferente e íntimamente ligada a su experiencia personal de la lectura, rescatan las influencias, los préstamos cuando no los plagios que consolidaron su propia escritura a la vez que su experiencia de vida (2003: 154).

En la forma tan peculiar que da a la legobiografía, Pitol encuentra una manera de confrontar las manifestaciones del poder textual y político, incluso del de la memoria y lo real. "El deseo de abolir las fronteras culturales se presenta en el mismo momento en que alguien fija las fronteras reales", escribe (Pitol, 1996: 144). Su fuga también atraviesa las fronteras entre lo público, característica emparentada a las memorias, y lo privado, lo que lo colocaría más cerca de la autobiografía según Francisco Rodríguez (2000). Pitol no confunde la memoria y la imaginación, las funde, contamina una a la otra y rinde, entre otras cosas y en palabras de Vélez, "justicia poética a la memoria histórica del pueblo mexicano" (2003: 155). Recuperemos, por ejemplo, lo que escribe con respecto a lo que él y su amigo, el escritor Caros Monsiváis, pensaban se tenía que hacer con los políticos y la situación del México de fines de los años cincuenta: "Hay que comenzar a reírse de todo, llegar al caos si es necesario, y hacer posible que los bienpensantes se intranquilicen, ya que buena parte de sus males y de los nuestros proceden de sus limitaciones. Reírse de ellos, ridiculizarlos, hacerlos sentir desamparados, sólo así podría cambiar algo" (Pitol, 1996: 47).

El arte de la fuga de Pitol enfatiza el material intertextual de la memoria y subraya la dificultad de definirse en ella. Es un texto que pone en fuga a la identidad personal, al definirla en términos de lo que se ha encontrado en otros. "Somos todo el pasado [escribe Pitol citando a Borges], somos nuestra sangre, somos la gente que hemos visto morir, somos los libros que nos han mejorado, somos gratamente los otros" (Pitol, 1996: 146). Así crea un espacio de saturación de voces, de diálogos múltiples con lo ajeno. 


\section{Molinos sin viento}

“Qué es la memoria, sino aquello que se quiere restaurar? ¿Y qué es aquello que se quiere restaurar, sino un deseo de consolación?" (2001: 10), escribe Angelina MuñizHuberman en este libro que es la segunda parte de sus seudomemorias y que puede leerse como colección de cuentos, como la suma de veintidós fragmentos de prosa poética o como una novela en donde se va esbozando el año en que Alberina, una niña de nueve años en 1945, refugiada española en la ciudad de México, vive en una casa en la calle de Santa Catarina en San Ángel. Y, aunque todo esto se corresponde con la vida de Muñiz-Huberman, como ha apuntado Guadalupe Pérez-Anzaldo, "no [se] pretende re-construir o aproximarse fidedignamente a una realidad pasada, una infancia específica. De lo que aquí se trata es de darle rienda suelta a la memoria y a la imaginación, sin privilegiar una sobre la otra, con el propósito de resarcir una identidad cuyo único punto de referencia es la palabra misma" (2001: 159).

El libro comienza así:

Nunca pensó que el ojo de la cerradura podía utilizarse para ver. Más bien creyó que era un ojo que la veía. Le tomó varios años averiguarlo. El día que lo descubrió se encontró con que las cosas nunca serán lo que parecen y que la visión es tan reducida y limitada que si no se aplica la imaginación la ignorancia será total. En una palabra, a sus nueve años descubrió la relatividad de este mundo. La relatividad, la ambigüedad y el punto de vista (9).

El texto, como puede notarse, está escrito en tercera persona, focalizado en Alberina, y la voz narrativa tiene una conciencia de sí misma como relatora muy grande, continuamente comenta lo que va ocurriendo y propone una poética de lectura cimentada en dichos relatividad, ambigüedad y punto de vista. Al referirse a este uso de la tercera persona, Muñiz-Huberman ha explicado que le sirve para hablar de sus recuerdos, para duplicar las ficciones, para aproximarse al pasado, cualquiera que éste sea o fuera. Y en esta idea de aproximación al pasado, de la posibilidad de hacerlo para encontrar un rincón en el que alojar alguna identidad, versa el libro entero, lo que se espera es recuperar la memoria porque, como nos cuenta en su libro, "sería una falta olvidar, sería algo peor: un pecado: un delito imperdonable... A recibir la herencia de los recuerdos. No olvides: no olvides: ha repetido su madre: no olvides" (Muñiz-Huberman, 2001: 49). En este caso, la herencia de los recuerdos es principalmente una herencia de exilio, una herencia de lo que no queda porque, como ha escrito MuñizHuberman en uno de sus poemas, "Desterrada aún sin haber nacido / ni siquiera me queda el recuerdo / ni siquiera puedo rebuscar en mi memoria / ni un olor, ni un sabor" (cit. por Pérez-Anzaldo, 2011: 158). Y Alberina/Angelina, siguiendo la orden materna, se dan a la tarea de asumirse como producto de ese exilio y, entonces, evitar la falta y recordar: "Otro rasgo que la perfila ya como exiliada es la manía de asentar por escrito y de datar. ¿Será porque quien vaga sin tierra se ilusiona con decir. 'Heme aquí, en este 
lugar, en tal día, de tal mes, de tal año, de tal hora, minuto y segundo'? Segurísimo" (2001: 11). Escribir es recordar y sólo se podrá recordar en aproximación.

Cargada con la obligación de la restauración de una memoria que no vivió, pero que se le encomienda a través de las historias de los padres, las fotografías en el desván de la casa, las cartas que las acompañan, la orden de su madre, lo que Alberina buscará será también el consuelo que le depararán las historias. Restaurará una memoria de lo real mediante los sueños, la imaginación, lo desconocido. Se trata de otra forma de acercarse al pasado y la tercera persona de la narración le permite un desdoblamiento en sujeto y objeto similar al que queda explicado en el siguiente fragmento del libro:

Un ojo que hace clic como el obturador de la cámara. Cámara lúcida. Ahora entiende esa palabra. Es la cámara que le persigue. Es la luz de la cámara. La iluminación súbita. El múltiple deslumbramiento:

El poderoso ojo de la creación.

El modesto ojo de la cerradura (2001: 128).

Es a través de ese ojo, esa perspectiva bifurcada de la cerradura y la creación, desdoblada en sujeto y objeto simultáneos, que Muñiz-Huberman queda extrañada, de sí y su memoria, en el sentido tanto de que busca lo ausente como de que lo crea. El exilio impuesto se vuelve un lugar para habitar. Su extrañamiento, como herramienta artística y como forma de vida, es parte y territorio de la nostalgia. Una nostalgia que intenta recuperar el lugar mítico que es el pasado, la patria, real o no, perdida por una colectividad. Es una distancia que inventa una referencia; una distancia extraña y que hace extrañar, que, además se sabe fragmentaria y singular. Angelina Muñiz considera al exilio, en todos los sentidos literales y metafóricos de la palabra, como una caída definitiva del paraíso que debe corregirse; y también, de forma irónica, ya que incluso a veces parece que lo disfruta, acepta sus paradojas y se acomoda en el desplazamiento: "Yo estuve en España por primera vez hace dos años — dice en 1991—y sólo por dos semanas. Pero España está en todas mis obras, aunque yo nunca haya estado. España ha sido una necesidad para mí: fue un vacío que se me convirtió en ficción" (Horno-Delgado, 1998: 148).

Este efecto de duplicidad del uso de la tercera persona, de recordar lo que no se tuvo nunca, de llenar un vacío impuesto, se subraya cuando, además en Molinos sin viento se incluyen los cuentos que la niña Alberina escribe junto con su amigo Carlo. La narración en tercera persona cede su lugar a un "nosotros" que imagina una escena de William S. Burroughs de visita en casa de los padres de Alberina arrastrando la historia del escritor norteamericano en México, pero contada desde los ojos de estos niños que lo ven sólo como una interferencia en un hormiguero en el jardín. Algo similar ocurre con los refranes y canciones que continuamente se citan, con las fotografías y cartas de amor encerradas en un baúl en el desván, inventadas o escritas por desconocidos y repetidas o conservadas por alguien más. Este uso de diferentes voces en una seudomemoria, en lugar del "yo" acostumbrado en la autoficción, conserva el encanto 
de la historia propia, pero adquiere también el de la historia ajena. "De las muchas maneras de aprender una es la de penetrar en otras vidas sin ser vista ni oída. Como testigo a larga distancia" (Muñiz-Huberman, 2001: 20).

Tal vez Muñiz-Huberman no tenga una memoria. Pero tiene la historia de una memoria. Una memoria narrada, producida por una identidad pluridimensional, "un ejercicio de introspección/reflexión y proyección/comunicación" (Pérez-Anzaldo, 2011: 58) sobre esta labor de "confesiones y confusiones, iluminaciones, desviaciones, horrores, bellezas" ( Muñiz-Huberman, cit. por Pérez-Anzaldo, 2011: 162) que leemos en las seudomemorias de Muñiz-Huberman.

\section{La ficción de Alice Munro: un puente flotante que esboza sombras}

Para terminar quiero referirme a la manera en la que los textos de ficción de Alice Munro hacen de la vacilación una forma medular semejante a la que hemos apuntado en las escrituras del yo analizadas. Me referiré a la imagen de un puente flotante de uno de sus relatos y a la estrategia del esbozo de sombras (side-shadowing) que John Gerlach (2007) ha apuntado como caracterísitca de la obra de Munro para explicar estas formas tan peculiares de memoria que hemos visto en los libros de Pitol y MuñizHuberman.

En su relato "Floating Bridge" (2001a), Alice Munro describe parte de la experiencia de atravesar un puente flotante en los despoblados caminos de Ontario. Dos personajes, un chico de diecisiete años y Jinny, la protagonista de la historia, una mujer mucho mayor, sudada, debilitada y mermada por la quimioterapia, se bajan del coche en el que van y, entonces:

[...] él soltó su mano y la dejó caminar sobre estos tablones que eran como la cubierta de un barco. Como la cubierta de un barco ascendían y descendían. Aunque no era un movimiento de olas, eran sus pasos, los de ella y de él, los que ocasionaban la elevación y la caída ligeras de las tablas que pisaban:

— ¿Sabes en dónde estás? —, preguntó él.

—iEn un muelle?" - dijo ella.

-En un puente. Un puente flotante (2001a: 83).

El puente flotante vuelve a ser descrito en el siguiente pasaje:

El leve movimiento del puente la hizo imaginar que todos los árboles y los juncos eran sostenidos por platos de tierra y que el camino era una cinta flotante también de tierra y que abajo todo era agua. Y el agua parecía estar quieta, pero no podía estarlo porque, si se intentaba mantener la vista en una de las estrellas reflejadas, se podía ver cómo parpadeaba y cambiaba de forma y se escabullía de la mirada. Después volvía a aparecer, pero tal vez no fuera la misma (85). 
Notemos cómo el relato se desdice y corrige: el agua parece quieta, pero no lo está, y refleja una estrella que brilla y se apaga para volverse a ver, aunque tal vez no se trate de la misma estrella. Así nosotros al leer todo el cuento vamos corrigiendo lo que esperamos y pensamos de lo que leemos, lo que puede y no puede pasar, lo que pasa y finalmente no pasará, lo que sucede y puede o pudo suceder.

John Gerlach (2007) retoma el concepto de esbozar sombras para explicar uno de los mecanismos que Munro suele utilizar. Se trata de una estrategia narrativa que supone al tiempo, los hechos y su comprensión como un campo de posibilidades; esbozar sombras es comprender un momento no solamente por lo que pasó, sino también por lo que podía haber pasado, lo que resulta en el énfasis en las posibilidades de la experiencia, la conciencia plena del presente como momento lleno de posibilidades temáticas y elecciones, cargado de resonancias retrospectivas y prospectivas (151). Así, en el final de "Floating Bridge", Jinny imagina a su marido extendiendo la mano frente a una mujer que le leerá el futuro: "Meciéndose en la orilla de su futuro. Sin importar. Lo que ella sintió fue una especie de compasión desenfadada. Un chasquido de dulce hilaridad, que obtenía lo mejor de todas sus llagas y vacíos, en ese momento dado" (Munro, 2001: 85). Las últimas palabras son la repetición en inversión de lo que Neal contestara, años atrás, a la pregunta que Jinny le haría después de regresar en su intento de abandonarlo: “‘AAlguna vez pensaste que vendrías tras de mí?’, le preguntó a Neal. "Claro. Dado el momento"' (56).

El relato no se clausura no sólo porque no sabemos qué sigue, sino porque se nos hace volver a una escena anterior, buscar y volver a buscar en la historia para poder entender qué ha pasado o qué pasará y para volver a llegar al puente flotante. El presente de Jinny entonces se intensifica, lo que parecería ser un respiro considerando su enfermedad y su desgastada relación con Neal. Estos finales que no cierran son comunes en Munro, sobre todo en sus últimas colecciones, y se deben a que ella piensa que la escritura es como la memoria, algo que, por un lado intenta capturarlo todo, establecer todas las conexiones, entender todos los mensajes, pero la ironía reside en que también sabe que esas conexiones podrían estar equivocadas, que los patrones podrían no ser, que de hecho no son, los reales, y que los intentos de totalidad pudieran ser nada más que traiciones. Un poco más adelante veremos de qué forma se refiere ella a textos que considera más cercanos a la realidad que lo que puede ser esta historia y veremos cómo esta forma de entender la memoria aparece también en esas reflexiones. Regresemos ahora al final sin clausura de "Floating Bridge". Ahí, las diferentes descripciones de lo que es experimentar un puente flotante, que se dicen y desdicen, las sombras que se esbozan en todo lo que sucede, son muy semejantes a la vacilación que hemos estado viendo en la escritura del yo de Pitol y de Angelina Muñiz-Huberman: se nos cuenta algo como real y, después de unas páginas, se nos vuelve a contar de otras maneras; el resultado son continuos acercamientos y distanciamientos, un mecerse continuo entre lo que es y no es, lo que fue y no, lo que será y podría haber sido.

Muchas de las historias de Munro parecen incluir versiones alternativas y de que fuera imposible terminarlas. Suelen cambiar de rumbo intempestivamente en el último 
momento gracias a palabras o enunciados marcados por cierta impaciencia epigramática. "for the time given", en "Floating Bridge", es un ejemplo de ello. Algo similar puede encontrarse en el último relato de esa misma colección, "The Bear Came Over the Mountain" (2001b), en donde un profesor universitario tiene que enfrentar que su mujer sufra la enfermedad de Alzheimer. El amoroso Grant, con una larga vida de adulterio, tiene que vivir con la decisión de Fiona, su mujer, de internarse en un asilo al notar cómo se le olvidan las cosas; tiene que atestiguar la relación que ella, en su espacio de olvido, establece con uno de los compañeros del lugar, Aubrey, y consolarla cuando la mujer de Aubrey, Marian, se lo lleva a casa. Cuando Grant se da cuenta que Fiona ya no lo reconoce y que ha decidido dejarse ir por el dolor de haber perdido a Aubrey, va a buscarlo y le pide a la esposa que lo regrese. Al final del relato, cuando aparentemente Grant y Marian salen juntos, él va a ver a Fiona para avisarle que le tiene una sorpresa (el regreso de Aubrey) y la encuentra en uno de esos intermitentes momentos en los que ella puede recordarlo otra vez. Después de un pequeño diálogo en el que lo que cada uno dice es exactamente lo que el otro habría dicho páginas atrás: al fin y al cabo el amor es mucho aprender a sentir qué es lo que el otro dice y necesita. Grant le anuncia que Aubrey está de regreso y ella le contesta que los nombres la eluden y añade:

—Estoy contenta de verte-, dijo ella, tomándolo de los lóbulos de las orejas.

- Pudiste simplemente haberte ido—, dijo ella. — Simplemente irte manejando sin que te importara en lo más mínimo abandonarme. Haberme abandonado. Abandonada.

Él sostuvo su rostro contra el pelo cano de ella, su cuero cabelludo rosado, el cráneo conformado dulcemente. Le dijo, "Ni de casualidad" (2001: 323).

Y es todo. La historia se acaba ahí en la página. Pero nosotros seguimos pensando sobre el significado de lo que leímos. ¿Es la historia de un momento de redención de Grant, que tuvo que ver a su mujer en otro mundo, olvidándolo a él, cuidando a otro y luego extrañando a ese otro hasta casi dejarse morir? ¿O es simplemente la historia de un marido cínico que regresa a Aubrey al asilo para así poder quedarse con otra mujer? El final, epigramático otra vez, esboza sombras: Grant bien podía haberse ido manejando y abandonarla, haberla abandonado, abandonándola. O como se quiera o pueda traducir lo que Fiona dice desde su memoria errática. Sabemos que el recuerdo que ella tiene de Grant no durará mucho, que tal vez no recuerde a Aubrey, que quién sabe si ha decidido seguir viviendo. Es más, no sabemos ya si todavía puede ella decidir algo, lo que es parte de la tragedia del Alzheimer. Y la respuesta de Grant, "Not a chance" ("Ni de casualidad"), negando el azar, pero dejando a la fortuna como la última palabra del relato, complica todo mucho más.

Nada está fijo, ni cerrado, todo vacila, está deslocalizado. Munro es experta en este arte de la incertidumbre (como lo ha llamado Andrea Szabo [2008]). Por eso no resulta curioso que el libro que Fiona tiene en su cuarto en el asilo sea Letters from Iceland, 
de W. H. Auden y Louis MacNiece, una pretendida guía de viaje que más bien es un experimento con las estrategias modernistas de representación, una colaboración entre fotógrafo (Auden) y escritor (MacNiece y el mismo Auden), a veces en verso y otras en prosa, sin narrativa continua, sin correlación entre imágenes fotográficas y verbales. ${ }^{3}$ Para Szabo, en ese libro Auden expone "la arbitrariedad de las convenciones narrativas al usarlas exageradamente" y cuestionar los códigos de representación accesibles a la cultura y, al mismo tiempo, reconociendo que es lo que se tiene para hacerlo (2008: 112). Al aludir a este otro texto, "The Bear Came Over the Mountain" subraya su propia capacidad de representar, la posibilidad de acceder y recordar la realidad y la necesidad de hacerlo. Holcombe considera que gran parte de la fuerza de Munro reside en esta forma de tratar las imperfecciones de la vida y el fracaso para hacer que ésta se ajuste a nuestras fantasías.

Al principio de este ensayo me referí a lo que Munro escribe sobre los últimos relatos del útlimo libro que ha publicado, Dear Life (2012), y que retomo ahora con unas frases más: "Las últimas cuatro piezas de este libro no son en realidad cuentos. Forman una unidad separada, una cargada de la calidad de la autobiografía, aunque a veces no tengan la calidad de los hechos. Creo que son lo primero y lo último - y lo más cercano- que tengo que decir sobre mi propia vida" (253). En el prefacio que escribió a The View from Castle Rock (2006) también se expresa en torno a la forma de este libro, que es uno de memorias personales, en términos de una vacilación parecida. Después de contar cómo estuvo durante varios años reuniendo material sobre la vida de algunos de sus familiares, muchos de los cuales habían dejado cartas o escritos memorialísticos, comenta cómo, al recontar esas historias, lo que obtuvo fueron "Sus palabras y las mías, nuestra re-creación de vidas, en un escenario determinado que resultó tan verdadero como cualquier noción que tengamos del pasado puede ser [...] de hecho, algunos de estos personajes se encuentran muy alejados de como eran en un principio y ya no puedo recordar cómo eran. Éstas son historias. Se puede decir que son historias que prestan mayor atención a la verdad de la vida que lo que normalmente lo hace la ficción. Pero no lo suficiente como para poder jurarlo" (ix).

Munro vacila entre el anzuelo que la realidad nos lanza, al que siempre parecemos estar impelidos, y la posibilidad de llegar a ella. Sus vacilaciones se vuelven estrategias narrativas que suponen al tiempo, los hechos y su comprensión como campos de posibilidades; así esboza sombras: cada momento se llena no solamente de lo que pasó, sino también de lo que podía haber pasado y lo que se piensa, se recuerda de lo que sucedió. El resultado es que se enfatizan las posibilidades de la experiencia, se hace

\footnotetext{
${ }^{3}$ Szabo menciona que se trata de un libro muy extraño que no es precisamente una guía de viajes y que es tan ambiguo que ha sido considerado un recuento de unas vacaciones, sólo como entretenimiento o, incluso, como un comentario político sobre Gran Bretaña. "La lectura de Munro de Letters from Iceland de Auden documenta el hecho de que no es posible acceder al conocimiento, que ningún deseo puede satisfacerse y que los escritores que tienen fe en la representación deberían saber las implicaciones que al hacerlo tienen en su propia obra" (2008: 106). (La traducción del texto de Szabo es mía.)
} 
conciencia de que los hechos que nos conforman estuvieron y siguen estando llenos de posibilidades temáticas y elecciones, cargados de resonancias retrospectivas y prospectivas.

Me parece que eso es lo que se consigue con las vacilaciones entre lo real y lo que no lo es planteadas también por Pitol y Muñiz-Huberman. Se trata de escrituras memorialísticas, autobiográficas, ficcionales altamente conscientes de que lo son y de que dicen, se desdicen y corrigen. Son escrituras que cuestionan y alertan sobre la posibilidad de escribir lo real, y nos hacen leerlas y pensarnos a nosotros mismos así: viviendo, atestiguando lo vivido, esperando lo que seguirá de lo que ocurrió, corrigiendo lo que esperamos y pensamos de lo que vivimos y leemos, lo que pudo y no pudo haber pasado, lo que pasó y finalmente no pasó, lo que pudo suceder. Y también son escrituras conscientes de que la realidad es muy compleja y estamos conformados por ella y su complejidad. "Creo - escribe Munro en una de las últimas historias de su último libro, una de las que considera más cercanas a ella - que si estuviera escribiendo ficción en lugar de estar recordando algo nunca le hubiera puesto a ella ese vestido" (2012: 291).

\section{Obras citadas}

Las traducciones son mías.

Alberca, Manuel. 2010. "Finjo ergo Bremen: la autoficción española día a día". Vera Toro, Sabine Schlickers y Ana LuENGO, eds. La obsesión del yo. La auto(r)ficción en la literatura española y latinoamericana. Madrid: Iberoamericana / Vervuert. Pp. 31-50.

CASAS, Ana. 2010. "La construcción del discurso autoficcional: procedimientos y estrategias". Vera TORO, Sabine SCHLICKERS y Ana LuENGO, eds. La obsesión del yo. La auto(r)ficción en la literatura española y latinoamericana. Madrid: Iberoamericana / Vervuert. Pp. 193-212.

GerLach, John. 2007. "To Close or Not to Close: Alice Munro's 'The Love of a Good Woman". Journal of Narrative Theory, 37.1. Pp. 146-158.

Horno-Delgado, Asunción y Angelina MuÑIZ-Huberman. 1998. "Un desnudamiento total: entrevista a Angelina Muñiz-Huberman". Confluencia, 1. Pp. 145-154.

LouIs, Annick. 2010. "Sin pacto previo explícito: el caso de la autoficción". Vera TORO, Sabine SCHLICKERS y Ana LUENGO, eds. La obsesión del yo. La auto(r)ficción en la literatura española y latinoamericana. Madrid: Iberoamericana / Vervuert. Pp. 73-96.

Munro, Alice. 2012. "Finale". Dear Life. Stories. Nueva York: Alfred A. Knopf. P. 253. 
2006. "Foreword. The View from Castle Rock. Toronto: Penguin Canada. Pp. xiii-xiv.

. 2001a. "Floating Bridge". Hateship, Friendship, Courtship, Loveship, Marriage. Nueva York: Alfred A. Knopf. Pp. 55-85. . 2001b. "The Bear Came Over the Mountain". Hateship, Friendship, Courtship, Loveship, Marriage. Nueva York: Alfred A. Knopf. Pp. 275-323. MuÑIz-Huberman, Angelina. 2001. Molinos sin viento. México: Aldus.

PÉREZ-ANZALDO, Guadalupe. 2011. "Exilio y memoria: los castillos interiores de Angelina Muñiz-Huberman”. Revista Destiempos, 28. Pp. 158-177.

Pitol, Sergio. 1996. El arte de la fuga. México: Era.

RODRÍGUEZ, Francisco. 2000. "El género autobiográfico y la construcción del sujeto autorreferencial”. Filología y Lingüistica, XXVI.2. Pp. 9-24.

SzABÓ F., Andrea. 2008. "Munro's Auden: 'Letters from Iceland"”. Hungarian Journal of English and American Studies, 1. Pp. 105-115.

VÉLEZ, Irma. 2009. "La legobiografía: de Jean Paul Sartre a Sergio Pitol". Confluencia, 2. Pp. 149-159. 